\title{
Ectomycorrhiza resilience and recovery to extreme flood events in Tuber aestivum and Quercus robur
}

\author{
P. W. Thomas ${ }^{1,2}$ iD \\ Received: 5 February 2021 / Accepted: 6 May 2021 / Published online: 13 May 2021 \\ (c) The Author(s) 2021
}

\begin{abstract}
Very little is known about the impact of flooding and ground saturation on ectomycorrhizal fungi (EcM) and increasing flood events are expected with predicted climate change. To explore this, seedlings inoculated with the EcM species Tuber aestivum were exposed to a range of flood durations. Oak seedlings inoculated with T. aestivum were submerged for between 7 and 65 days. After a minimum of 114-day recovery, seedling growth measurements were recorded, and root systems were destructively sampled to measure the number of existing mycorrhizae in different zones. Number of mycorrhizae did not display correlation with seedling growth measurements. Seven days of submersion resulted in a significant reduction in mycorrhizae numbers and numbers reduced most drastically in the upper zones. Increases in duration of submersion further impacted mycorrhizae numbers in the lowest soil zone only. T. aestivum mycorrhizae can survive flood durations of at least 65 days. After flooding, mycorrhizae occur in higher numbers in the lowest soil zone, suggesting a mix of resilience and recovery. The results will aid in furthering our understanding of EcM but also may aid in conservation initiatives as well as providing insight for those whose livelihoods revolve around the collection of EcM fruiting bodies or cropping of the plant partners.
\end{abstract}

Keywords Flooding $\cdot$ Climate change $\cdot$ Soil saturation $\cdot$ Quercus robur (oak) $\cdot$ Tuber aestivum (summer truffle) . Mycorrhiza

\section{Introduction}

The term mycorrhiza describes a symbiotic relationship between plants and fungi, in which the plant partner provides photosynthetically derived carbon in exchange for nutrients (Smith and Read 2010). At least $86 \%$ of angiosperms form mycorrhiza and arbuscular mycorrhiza (AM), ectomycorrhiza $(\mathrm{EcM})$ and ericoid mycorrhiza $(\mathrm{ErM})$ are geographically the most widespread (Brundrett 2009). AM species are the most abundant and these appear relatively tolerant to hostile conditions such as high levels of soil salinity, occurring in wetland environments from calcareous fen to saltmarsh and mangroves (Rozema et al. 1986; Zhouying et al. 2016). However, AM are not ubiquitous in waterlogged environments (Radhika and Rodrigues 2007) and the degree

P. W. Thomas

paul.thomas@stir.ac.uk

1 Faculty of Natural Sciences, University of Stirling, Stirling FK9 4LA, UK

2 Mycorrhizal Systems Ltd, Lancashire PR25 2SD, UK of colonisation may decrease with increased flooding along wetland gradients (Wang et al. 2010). The occurrence of some AM species within waterlogged environments has been suggested, in some cases, to be driven by the presence of well-developed aerenchyma (air chambers) within the root system that may reduce anaerobiosis stress, such as low oxygen tension and the accumulation of reduced toxic substances (Rozema et al. 1986; Wang et al. 2010). These chambers benefit the plant but also its mycorrhizal endophyte. Aerenchyma tissue, through the facilitation of gas exchange from above ground plant parts to the rhizosphere, may influence the survival of mycorrhizal fungi and other aerobic microorganisms (Cooke and Lefor 1998).

In contrast to $\mathrm{AM}$, the nature of EcM with an intercellular interface presents a greater structural vulnerability to saturated soil conditions. Indeed, it has been hypothesised that low EcM levels in some field studies may be an indication of regularly flooded soils (Katanić et al. 2015). However, the mycelia produced by EcM fungi can be categorised as either hydrophobic or hydrophilic and species within the latter category may be better able to resist saturated soil conditions. Hydrophobicity may be an adaptation to retain water in dry 
soil and prevent inundation in wet soil (Unestam and Sun 1995; Barnes et al. 2018). Although the impact of drought and water scarcity on microbial communities, including EcM, has been fairly well studied, there are comparatively few reports that focus on flooding and soil saturation (Johnson 2018). However, there are some intriguing insights. For example, Alnus glutinosa (L.) Gaertn. is a tree species that occurs in areas with permanent high ground water levels and frequent inundation. Despite this, A. glutinosa may associate with up to 40 different EcM species although in one study, it was observed that dryer soils yielded nearly $3 \times$ the unique EcM species of wetter soils (Tedersoo et al. 2009). A. glutinosa may also form AM associations and this decline in EcM richness in wetter conditions may be symptomatic of AM dominance in such circumstances, although this has not been experimentally verified.

Differing responses of hydrophobic or hydrophilic EcM has also been verified experimentally. For example, in a study with the tree species Pinus sylvestris, the EcM species Suillus bovinus proved particularly vulnerable to high water levels, with colonisation of the root system unable to occur when the system was flooded for just 2 min a day, four times a week. By contrast, Thelephora terrestris, Laccaria laccata and Hebeloma crustuliniforme were resilient to such conditions (Stenström 1991). General EcM colonisation has been shown to be inhibited at high soil moisture levels (Lodge 1989) and declines in EcM in response to waterlogged conditions have also been observed outside the laboratory. Field observations of a Salix viminalis L. plantation in England (UK) present declines in both the abundance and species richness of EcM communities in response to increased ground saturation caused by localised extreme weather events. Interestingly, these changes were observed without any alteration in major soil physio-chemical properties driven by potentially anoxic soil conditions, having been recorded. Further, when the results were subdivided, it was observed that this decline did not occur in hydrophilic EcM (Barnes et al. 2018). Although such studies allow us to draw conclusions such that EcM in general show sensitivity to flooding, with significant interspecies variation, there is much detail we still do not know. For example, how long can established EcM survive waterlogged conditions and what is the resilience and recovery within the system? The very basic question of how long EcM can tolerate saturated conditions has not previously been addressed.

Flooding and extreme precipitation events have recently been increasing and anthropogenically driven climate change is thought to be a driving force. Globally, the number of floods and other hydrological events have increased fourfold since 1980 and have doubled since 2004 (Hov et al. 2018). Projected atmospheric warming is forecast to increase future flood risk at a global scale. For example, with a global warming of $4{ }^{\circ} \mathrm{C}$, countries representing more than $70 \%$ of the global population are projected to face increases in flood risk in excess of 500\% (Alfieri et al. 2017). In the face of such dramatic change, investigating how EcM respond to such events may seem trivial but understanding such responses are important for a number of reasons. Firstly, a deeper knowledge will allow us to better understand the impact of such events on ecosystems at a range of spatiotemporal scales and can help inform conservation initiatives. Secondly, a range of food crops such as the majority of temperate nut production as well as commercial timber activities are dominated by species that form EcM. By better understanding the resilience and tolerances of EcM, we can better protect these industries. Thirdly, the local collection of fruit bodies from a number of EcM fungi may be quite significant from a socioeconomic point of view (e.g. Saito and Mitsumata 2008) as well as forming an important component of local cultural identity (Samils et al. 2008). Economically, the most important edible mycorrhizal fungi are from the genus Tuber, the hypogeal fruiting bodies of which are known collectively as truffles. In a recent analysis of non-wood forest products of Europe, the economic value of harvested truffles was estimated at $\sim 3.1$ billion $€$ $\mathrm{yr}^{-1}$ (Lovrić et al. 2020). Truffles are widely cultivated, we know they face an uncertain future due to predicted climate change (Thomas and Büntgen 2019) and may be sensitive to soil moisture (Olivera et al. 2014) but a more nuanced understanding of the biology may allow us to better prepare.

In order to better understand the impact of flooding on EcM, tree saplings inoculated with Tuber aestivum (the summer truffle) were subjected to submersion for a range of time periods from 7 to 65 days. The impact on EcM was assessed after a recovery period. T. aestivum was chosen so that the results could also help inform truffle cultivators and managers of naturally producing truffle woods, to prepare and respond to flood events.

\section{Materials and methods}

\section{Preparation of inoculated seedlings}

To prepare the inoculated saplings, acorns from mature Quercus robur trees in UK seed region 403 (see: Herbert et al. 1999) were collected in autumn 2014. Seed was cleaned for 5 min with 5\% sodium hypochlorite and then thoroughly rinsed to remove all residue. The seed was sown in spring 2015 into a potting mix of $70 \%$ sandy loam and $30 \%$ perlite. The mix was heat treated and the $\mathrm{pH}$ was adjusted to 7.6 using ground lime. Individual plants were inoculated with a sporal solution of macerated T. aestivum sporocarps of English provenance, with no site selection criteria of inoculum source applied. Each plant received a dose equivalent to $1 \mathrm{~g}$ of fresh sporocarp, applied directly and 
whilst in the growing medium. The plants were grown-on for a full season, under glass in Lancashire (UK) in $17 \mathrm{~cm}$ deep Rootrainer pots with a volume of $350 \mathrm{cc}$ (Tildenet Group Ltd, UK). In October 2015, a subset of plants was destructively sampled to confirm colonisation with $T$. aestivum using the protocol outlined under Analysis Methodology. Seed that had not formed a shoot by this time point were eliminated from the experiment, as were any seedling under $5 \mathrm{~cm}$.

\section{Submersion treatment}

On the $25^{\text {th }}$ of January 2016, all plants were removed from the glasshouse and treatment groups were suspended in an immersion tank holding rainwater, in the open air. On the same day, 10 plants for a control group were placed on a growing table adjacent to the immersion tank. The water level of the immersion tank was maintained at approximately $1 \mathrm{~cm}$ above the soil line of the pots. No water exchange was carried out, nor intentional mixing/agitation of the water column but additional water was carefully added when needed, to maintain a constant depth. This methodology was to recreate waterlogged soil conditions and ensured that the roots were fully submerged, whilst the dormant seedling stem remained above the water line. At eight different time points, 10 plants were removed from the immersion tank and placed on a growing bench, adjacent to the tank. The eight time points ranged from 7 days submersion to 65 days submersion, in 7-day intervals. The number of timepoints that could be analysed was constrained by resource-availability but were spaced in response to the authors' observation of a truffle-orchard that flooded for over 14 days without apparent deleterious impact. After removal from the submersion tank, all plants were placed on a growing bench until August-September 2016 when they were destructively sampled. All plants were sampled on the same dates, being 179-188 days after the onset of submersion, to mitigate any potential impact of them being exposed to different weather conditions. However, this meant that the post-treatment time (prior to analysis) of the treatment groups differed by as much as 58 days. The recovery periods for the 8 treatment groups were therefore $172-181,164-173,156-165$, 148-157, 140-149, 130-139, 122-131, and 114-123 days, respectively (full details are presented in Table $\mathrm{S} 1$ of Online Resource 1).

\section{Analysis methodology}

During the analysis period, all plants were destructively sampled. First, the height of each plant was measured with a measuring stick from the soil-line to the tip of the growing point. The number of attached leaves were also counted. Finally, the Rootrainer pot was opened and the root system of each plant was carefully washed to remove the majority of the growing media. The washed root system was placed against a measuring stick and the whole root was cut into three equal segments: the upper third of the root system (upper), the middle section (middle) and the bottom third (bottom). Within each root zone, 100 root tips were examined microscopically giving 300 root tips per plant and a total of 3000 for each treatment group. To prevent selection bias, once a root segment was placed under the dissecting microscope, the first root tip in the field of view was analysed and then each subsequent root tip was checked, moving along the field of view in a methodical manner, until 100 tips were counted. Each root tip was analysed for the presence/absence of T. aestivum EcM using the descriptions of Zambonelli et al. (1993).

\section{Results}

Seedling survival was $100 \%$ in all categories. A simple linear regression revealed a significant relationship between leaf counts and the final height of seedlings $(\mathrm{F}(1,78)=13.94$, $p=0.0004)$ with an $R^{2}$ of 0.1516 . However, the total number of measured T. aestivum mycorrhizae per plant, from a per-plant root-tip count of 300 , showed no relationship to seedling height $(\mathrm{F}(1,78)=0.009027, p=0.9246)$ or seedling leaf count $(\mathrm{F}(1,78)=8.743 \mathrm{e}-007, p=0.9993)$. Variations in mycorrhizae colonisation are therefore independent of seedling height or the number of retained leaves (data presented graphically in Fig. S1 of Online Resource 1).

Overall, the total number of recorded T. aestivum mycorrhizae per plant, from a per-plant root-tip count of 300 , was significantly lower in the combined submersion treatment group (14.75) than in the control (26.5) $(t(268)=-2.917$, $p=0.0038$ ). Looking at the different root horizons separately in the control and combined treatment groups, there was a statistically significant difference between mean values for profile depth between control and combined treatment groups as determined by a one-way ANOVA $(F(5,264)=5.168, p=0.0002)$. Post hoc Tukey's HSD tests revealed that the mycorrhizae count in the upper (9.64) and middle zone (12.67) were statistically significantly lower than the bottom zone (21.95) in the treatment group at the 0.05 level of significance (see Fig. 1 and Table 1).

The upper root zone mycorrhizae count of the treatment group was also statistically significantly lower than the upper root zone in the control group (31.00) but all other comparisons were not significant. The impact of submersion is therefore displayed significantly in the upper and mid layers of the root zone.

Although the mycorrhizae counts were lower in the upper root zones of the treatment groups root system, the duration of flood event did not appear to be as influential as expected. 


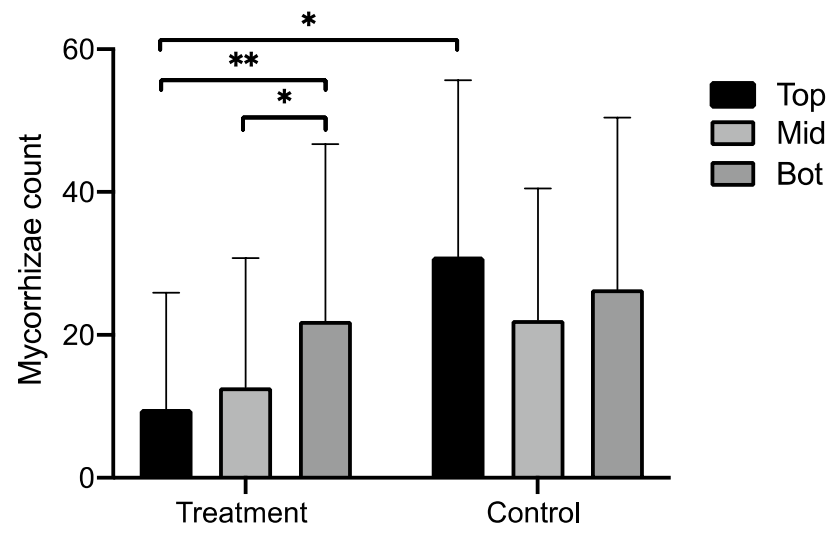

Fig. 1 Combined T. aestivum mycorrhizae counts on root samples from plants in the treatment groups and the control group. Results are separated by depth of profile into the upper (Top), middle (Mid) and bottom (Bot) root zone. Error bars are standard deviation. Bars joined by brackets are significantly different at $p<0.05$ (*) or $p<0.01$ (**) using a post hoc Tukey's HSD, all other comparisons between means were not significant $(p>0.05)$. Created with Prism 9 for macOS

The total mycorrhizae counts for seedlings submerged at the first time point (day 7) vs the control were significantly different $(t(58)=-2.1864, p=0.0164)$, but increased duration of flood event did not seem to impact this further. A simple linear regression revealed no significant relationship between duration of submersion from 7 to 65 days and total seedling mycorrhizae counts $(\mathrm{F}(1,238)=3.186, p=0.0755)$ with an $R^{2}$ of 0.01321 . However, if the root zones are analysed independently, then for the bottom layer only, there is a significant relationship between duration of submersion from 7 to 65 days and mycorrhizae counts $(\mathrm{F}(1,78)=4.473$, $p=0.0376$ ) with an $R^{2}$ of 0.05424 (see Table 1 and Fig. S2 of Online Resource 1). The shortest submersion period in this study (7 days) is therefore enough time to significantly impact mycorrhizae, but beyond this time point, there is only a relationship between submersion time and mycorrhizae counts in the lowest root zone.

\section{Discussion}

Full submersion for 7 days is enough to cause a significant impact on EcM numbers. However, beyond this time-point, the duration of submersion appears to be less important than expected. Extending the duration of submersion, up to a full 65 days, does not further add to this deleterious impact and the survival of EcM for this duration is unexpected. The division of root systems into three distinct root zones allows some further exploration of the results. There does not appear to be any difference between the lower and middle root zones in terms of mycorrhizae numbers between the treatment and control groups, but in the upper root zone, there is. Stratification of temperature, methane and dissolved oxygen occurs in even shallow bodies of water (Ford et al. 2002). EcM requires oxygen for respiration, and within
Table 1 Statistical analysis results for post hoc Tukey's HSD tests between EcM observations for the upper (Top), middle (Mid) and bottom (Bot) root zones of the treatment groups and the upper (CTop), middle (CMid) and bottom (CBot) root zones of the control group. Linear regression results for EcM observations of the upper (Top), middle (Mid) and bottom (Bot) root zones vs submersion time (Sub) and all zones combined (Combined) vs submersion time are also displayed. 95\% Confidence interval $(\mathrm{CI})$ represents the difference between means for multiple comparison tests and of the slope, for linear regression. Significant results with $p<0.05$ marked with an asterisk (*)

\begin{tabular}{lllll}
\hline & Mean diff & $95 \%$ CI & $p$ value & $R^{2}$ \\
\hline Tukey's multiple comparison & & & & \\
Top vs. Mid & -3.025 & -12.25 to 6.196 & 0.9353 & - \\
Top vs. Bot & -12.31 & -21.53 to -3.091 & $0.0022^{*}$ & - \\
Top vs. CTop & -21.36 & -40.92 to -1.801 & $0.0233^{*}$ & - \\
Top vs. CMid & -12.46 & -32.02 to 7.099 & 0.4489 & - \\
Top vs. CBot & -16.76 & -36.32 to 2.799 & 0.14 & - \\
Mid vs. Bot & -9.288 & -18.51 to -0.06613 & $0.0472^{*}$ & - \\
Mid vs. CTop & -18.34 & -37.90 to 1.224 & 0.0804 & - \\
Mid vs. CMid & -9.438 & -29.00 to 10.12 & 0.736 & - \\
Mid vs. CBot & -13.74 & -33.30 to 5.824 & 0.336 & - \\
Bot vs. CTop & -9.05 & -28.61 to 10.51 & 0.7692 & - \\
Bot vs. CMid & -0.15 & -19.71 to 19.41 & $>0.9999$ & - \\
Bot vs. CBot & -4.45 & -24.01 to 15.11 & 0.9867 & - \\
CTop vs. CMid & 8.9 & -17.18 to 34.98 & 0.9241 & - \\
CTop vs. CBot & 4.6 & -21.48 to 30.68 & 0.9959 & - \\
CMid vs. CBot & -4.3 & -30.38 to 21.78 & 0.997 & - \\
Linear regression & & -0.2600 to 0.01281 & 0.0755 & 0.01321 \\
Combined vs. Sub & - & -0.1780 to 0.2030 & 0.8962 & 0.00022 \\
Top vs. Sub & - & -0.2951 to 0.1265 & 0.4286 & 0.00805 \\
Mid vs. Sub & - & -0.5806 to -0.01756 & $0.0376 *$ & 0.05424 \\
Bot vs. Sub & - & & &
\end{tabular}


saturated soil, oxygen gradients also exist with the diffusion of oxygen being further constrained by soil texture and porosity (Neira et al. 2015); the changes to physiochemical properties in such conditions may also be significant (Vepraskas et al. 2001). As a whole, these changes may in part explain the observed reductions in T. aestivum EcM, to flooding. If the expectation of greater oxygen diffusion at the surface layer and progressively more hypoxic conditions with depth is correct, the upper zones would likely be less responsive to flooding. Instead, we see the inverse, and this may be explained by recovery methods.

The post-submersion observation of EcM may represent resilience, recovery through new mycorrhizae development or, most likely, a combination of both. Due to the elapsed time between the end of treatment within each group and the analysis date, there is potential for a mycorrhizal recovery method (or methods) occurring prior to analysis.

T. aestivum belongs to the Ascomycota phylum, a group in which spores are formed within an ascus and this may afford the spores some mechanical protection. Mycorrhizae development from spores is well understood and some species within the Rhizopogon genus have shown increased ability to infect tree roots, with duration in the spore bank: up to a current maximum tested age of 4 years (Bruns et al. 2009). Further, species within the Tuber genus can survive significant periods of storage in inhospitable environments, such as drying for 3 months (Bonito et al. 2012) or transit through mammalian digestive tracts (Piattoni et al. 2014). Persistence of spores from the initial inoculation of seedlings within this experiment, therefore, represents one possible method by which new roots may become infected post-submersion. T. aestivum may also form clusters of aggregated hyphae, including as fruiting body attachment structures (Deveau et al. 2019), and these can act as survival refugia with nutritional stores from which mycelial expansion may occur. It is also a possibility that mycelial fragments may also survive within micro-pockets of aeration within the soil matrix (see Fig. 2).

Development of new EcM from such refugia is likely aided by carbon transfer from the plant partner. During periods of host plant photosynthetic dormancy, carbon may arise from stored reserve compounds and hydrolyzed during cool-weather events (Le Tacon et al. 2013). Spatial differences in refugia, such as a greater residual spore load in the lower zone, mechanically transported by repeated watering post-inoculation may explain why EcM levels are higher in the lowest zone post-submersion. Further investigation is needed to identify if such differences exist.

Another factor that needs to be considered is that the treatment groups also differ in their recovery time, a term here applied to the duration between the end of the submersion period and the analysis date. The group with the shortest submersion duration (7 days) had a greater potential recovery time of 58 days compared with the group subjected to the greatest submersion time. However, it is possible that increased recovery time may not have a positive impact on mycorrhizae development. For example, T. aestivum favours alkaline conditions (Thomas 2012) and the soil $\mathrm{pH}$ modifier used within
Fig. 2 Diagrammatic representation of possible EcM recovery and resilience methods to flood events. These include the development of new mycorrhizae from: existing mycorrhizae, survival structures as aggregated hyphae, mycelial survival in aerated micro-pockets and the existing spore bank. Created with Biorender.com

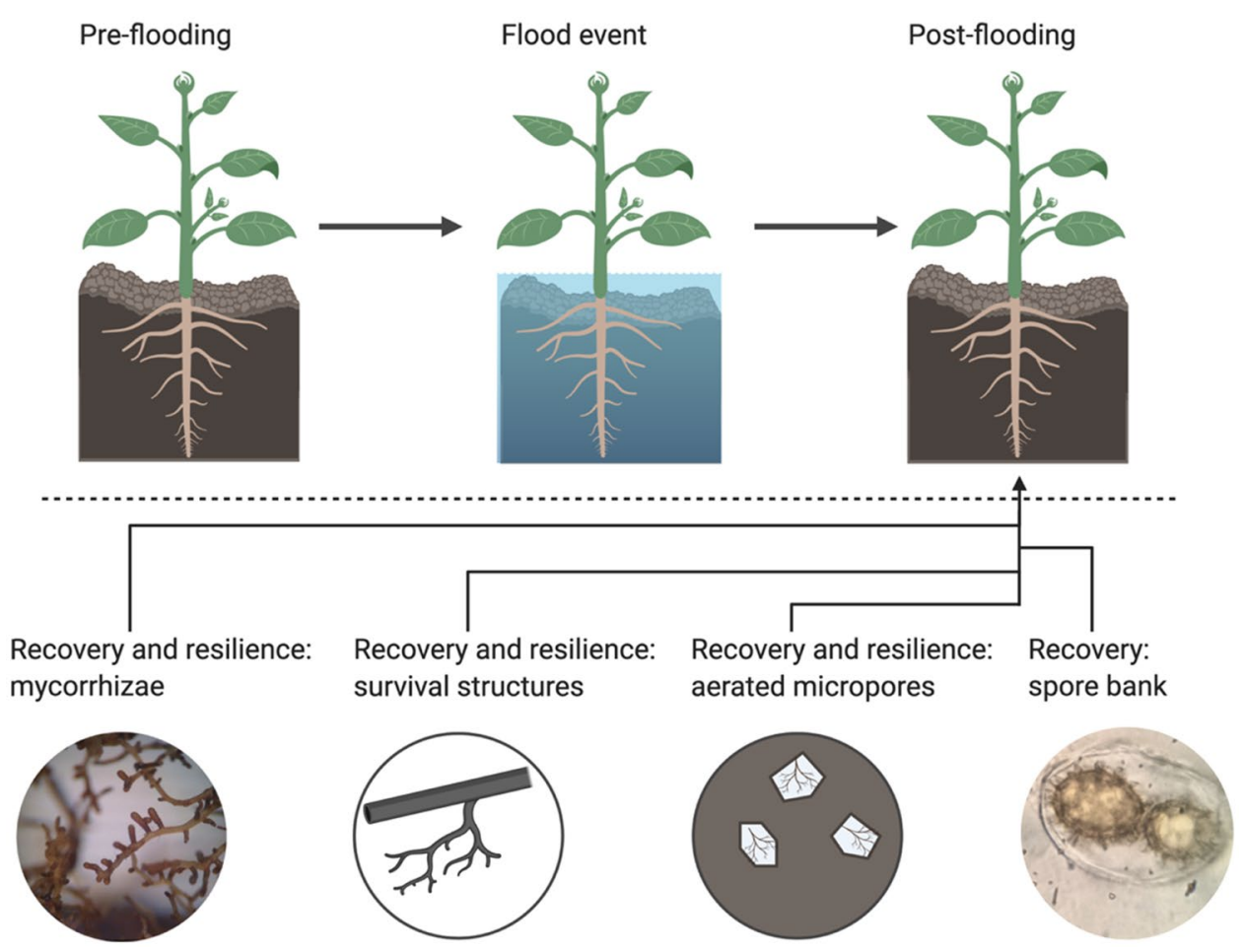


this experiment is water soluble $\left(\mathrm{CaCO}_{3}\right)$ and especially so in rainwater which has a higher concentration of dissolved $\mathrm{CO}_{2}$. Therefore, if submersion causes a change to sub-optimal $\mathrm{pH}$ levels, a longer 'recovery time' in such conditions may be deleterious. Unfortunately, changes in substrate physio-chemical properties post-submersion were not analysed in this study. Further, experimentation is needed to assess if these differences in recovery time are significant and what changes to the soil physiochemical properties have occurred.

\section{Conclusion}

The results of this study support, and in a dose-dependent manner, the previously suggested impacts that flooding can have on EcM. AM tend to dominate in soils frequently subject to saturation, but here, it is shown that even though the relative quantity of EcM on a host plant is significantly damaged with short durations of flooding, they also display a surprising degree of resilience to inhospitable conditions. So much so, that even after 65 days of flooding, there is persistence of EcM, most likely from a mix of resilience and recovery methods. Further, the surprisingly higher levels of EcM, post-flooding, in the lower soil zones may be indicative of the importance of recovery mechanisms.

These results provide some insight into the tolerances of EcM to saturated soils. The results are not only of benefit to mycologists but also have implications for ecologists working on a wide range of plant community and soil-plant interaction topics. Finally, the results also have a practical element for management in timber and nut production using trees that form EcM and especially for truffle-cultivators, where climate change presents an expectation for extreme rainfall events and flooding to increase in severity and frequency.

Supplementary information The online version contains supplementary material available at https://doi.org/10.1007/s00572-021-01035-4.

Acknowledgements With thanks to D K Paskin for care of the plants used within this study and prior to analysis.

Author contribution Study design, its analysis and creation of the manuscript are the sole work of PT.

Funding Materials and equipment supplied by Mycorrhizal Systems Ltd.

Availability of data and material Full datasets available on request.

Open Access This article is licensed under a Creative Commons Attribution 4.0 International License, which permits use, sharing, adaptation, distribution and reproduction in any medium or format, as long as you give appropriate credit to the original author(s) and the source, provide a link to the Creative Commons licence, and indicate if changes were made. The images or other third party material in this article are included in the article's Creative Commons licence, unless indicated otherwise in a credit line to the material. If material is not included in the article's Creative Commons licence and your intended use is not permitted by statutory regulation or exceeds the permitted use, you will need to obtain permission directly from the copyright holder. To view a copy of this licence, visit http://creativecommons.org/licenses/by/4.0/.

\section{References}

Alfieri L, Bisselink B, Dottori F, Naumann G, de Roo A, Salamon P, Wyser K, Feyen L (2017) Global projections of river flood risk in a warmer world. Earth's Future 5(2):171-182

Barnes CJ, van der Gast CJ, McNamara NP, Rowe R, Bending GD (2018) Extreme rainfall affects assembly of the root-associated fungal community. New Phytol 220(4):1172-1184

Bonito G, Smith ME, Brenneman T, Vilgalys R (2012) Assessing ectomycorrhizal fungal spore banks of truffle producing soils with pecan seedling trap-plants. Plant Soil 356(1-2):357-366

Brundrett MC (2009) Mycorrhizal associations and other means of nutrition of vascular plants: understanding the global diversity of host plants by resolving conflicting information and developing reliable means of diagnosis. Plant Soil 320(1-2):37-77

Bruns TD, Peay KG, Boynton PJ, Grubisha LC, Hynson NA, Nguyen NH, Rosenstock NP (2009) Inoculum potential of Rhizopogon spores increases with time over the first 4 yr of a $99-y r$ spore burial experiment. New Phytol 181(2):463-470

Cooke JC, Lefor MW (1998) The mycorrhizal status of selected plant species from Connecticut wetlands and transition zones. Restor Ecol 6(2):214-222

Deveau A, Clowez P, Petit F, Maurice JP, Todesco F, Murat C, Harroué M, Ruelle J, Le Tacon F (2019) New insights into black truffle biology: discovery of the potential connecting structure between a Tuber aestivum ascocarp and its host root. Mycorrhiza 29(3):219-226

Ford PW, Boon PI, Lee K (2002) Methane and oxygen dynamics in a shallow floodplain lake: the significance of periodic stratification. Hydrobiologia 485(1-3):97-110

Herbert R, Samuel S, Patterson G (1999) Using native stock for planting native trees and shrubs. Forestry Commission, Edinburgh (United Kingdom)

Hov Ø, Cubasch U, Fischer E, Höppe P, Iversen T, Kvamstø NG, W Kundzewicz Z, Rezacova D, Rios D, Duarte Santos F et al (2013) Trends in extreme weather events in Europe: implications for national and European Union adaptation strategies. 2013, updated 2018

Johnson D (2018) Water, water everywhere... but how does it affect the functional diversity of ectomycorrhizal fungi? New Phytol 220(4):950-951

Katanić M, Grebenc T, Orlović S, Matavuly M, Kovačević B, Bajc M, Kraigher H (2015) Ectomycorrhizal fungal community associated with autochthonous white poplar from Serbia. iForest 9(2):330

Le Tacon F, Zeller B, Plain C, Hossann C, Bréchet C, Robin C (2013) Carbon transfer from the host to Tuber melanosporum mycorrhizas and ascocarps followed using a $13 \mathrm{C}$ pulse-labeling technique. PLoS One 8(5)

Lodge D (1989) The influence of soil moisture and flooding on formation of VA-endo-and ectomycorrhizae in Populus and Salix. Plant Soil 117(2):243-253

Lovrić M, Da Re R, Vidale E, Prokofieva I, Wong J, Pettenella D, Mavsar R (2020) Non-wood forest products in Europe-a quantitative overview. Forest Policy Econ 116:102175

Neira J, Ortiz M, Morales L, Acevedo E (2015) Oxygen diffusion in soils: understanding the factors and processes needed for modeling. Chil J Agr Res 75:35-44

Olivera A, Bonet JA, Oliach D, Colinas C (2014) Time and dose of irrigation impact Tuber melanosporum ectomycorrhiza proliferation 
and growth of Quercus ilex seedling hosts in young black truffle orchards. Mycorrhiza 24(1):73-78

Piattoni F, Amicucci A, Iotti M, Ori F, Stocchi V, Zambonelli A (2014) Viability and morphology of Tuber aestivum spores after passage through the gut of Sus scrofa. Fungal Ecol 9:52-60

Radhika KP, Rodrigues BF (2007) Arbuscular mycorrhizae in association with aquatic and marshy plant species in Goa. India Aquat Bot 86(3):291-294

Rozema J, Arp W, Van Diggelen J, Van Esbroek M, Broekman R, Punte H (1986) Occurrence and ecological significance of vesicular arbuscular mycorrhiza in the salt marsh environment. Acta Bot Neerl 35(4):457-467

Saito H, Mitsumata G (2008) Bidding customs and habitat improvement for matsutake (Tricholoma matsutake) in Japan. Econ Bot 62(3):257-268

Samils N, Olivera A, Danell E, Alexander SJ, Fischer C, Colinas C (2008) The socioeconomic impact of truffle cultivation in rural Spain. Econ Bot 62(3):331

Smith SE, Read DJ (2010) Mycorrhizal symbiosis. Academic Press, Cambridge, UK

Stenström E (1991) The effects of flooding on the formation of ectomycorrhizae in Pinus sylvestris seedlings. Plant Soil 131(2):247-250

Tedersoo L, Suvi T, Jairus T, Ostonen I, Põlme S (2009) Revisiting ectomycorrhizal fungi of the genus Alnus: differential host specificity, diversity and determinants of the fungal community. New Phytol 182(3):727-735
Thomas PW (2012) The role of $\mathrm{pH}$ in Tuber aestivum syn. uncinatum micorrhiza development within commercial orchards. Acta Mycologica 47(2)

Thomas P, Büntgen U (2019) A risk assessment of Europe's black truffle sector under predicted climate change. Sci Total Environ 655:27-34

Unestam T, Sun Y-P (1995) Extramatrical structures of hydrophobic and hydrophilic ectomycorrhizal fungi. Mycorrhiza 5:301-311

Vepraskas MJ, Faulkner SP, Richardson JL (2001) Redox chemistry of hydric soils. Wetland soils: Genesis, hydrology, landscapes, and classification 85-106

Wang Y, Qiu Q, Yang Z, Hu Z, Tam NF, Xin G (2010) Arbuscular mycorrhizal fungi in two mangroves in South China. Plant Soil 331(1-2):181-191

Zambonelli A, Salomoni S, Pisi A (1993) Caratterizzazione anatomomorfologica delle micorrize di Tuber spp. su Quercus pubescens Willd. Micol Ital 3:73-90

Zhouying XU, Yihui BA, Jiang Y, Zhang X, Xiaoying LI (2016) Arbuscular mycorrhizal fungi in wetland habitats and their application in constructed wetland: a review. Pedosphere 26(5):592-617

Publisher's Note Springer Nature remains neutral with regard to jurisdictional claims in published maps and institutional affiliations. 